\title{
A framework for investigating large-scale patterns as an alternative to precipitation for downscaling to local drought
}

\author{
Erin Towler ${ }^{1} \cdot$ Debasish PaiMazumder $^{1} \cdot$ Greg Holland $^{1}$
}

Received: 15 December 2014 / Accepted: 3 April 2016 / Published online: 18 April 2016

(C) The Author(s) 2016. This article is published with open access at Springerlink.com

\begin{abstract}
Global Climate Model (GCM) projections suggest that drought will increase across large areas of the globe, but lack skill at simulating climate variations at local-scales where adaptation decisions are made. As such, GCMs are often downscaled using statistical methods. This study develops a 3-step framework to assess the use of large-scale environmental patterns to assess local precipitation in statistically downscaling to local drought. In Step 1, two statistical downscaling models are developed: one based on temperature and precipitation and another based on temperature and a large-scale predictor that serves as a proxy for precipitation. A key component is identifying the large-scale predictor, which is customized for the location of interest. In Step 2, the statistical models are evaluated using NCEP/NCAR Reanalysis data. In Step 3, we apply a large ensemble of future GCM projections to the statistical models. The technique is demonstrated for predicting drought, as measured by the Palmer Drought Severity Index, in South-central Oklahoma, but the framework is general and applicable to other locations. Case study results using the Reanalysis show that the large-scale predictor explains slightly more variance than precipitation when predicting local drought. Applying future GCM projections to both statistical models indicates similar drying trends, but demonstrates notable internal variability. The
\end{abstract}

Electronic supplementary material The online version of this article (doi:10.1007/s00382-016-3116-5) contains supplementary material, which is available to authorized users.

Erin Towler

towler@ucar.edu

1 Regional Climate Section, MMM, NESL, National Center for Atmospheric Research (NCAR), P.O. Box 3000, Boulder, CO 80307-3000, USA case study demonstrates: (1) where a large-scale predictor performs comparably (or better) than precipitation directly, then it is an appealing predictor choice to use with future projections, (2) when statistically downscaling to local scales, it is critical to consider internal variability, as it may be more important than predictor selection.

Keywords Drought $\cdot$ Large-scale patterns $\cdot$ Statistical downscaling $\cdot$ Climate models

\section{Introduction}

Drought is a critical challenge facing societies around the world, exacerbated by growing demands on water resources in an era of climate variability and change (Eriyagama et al. 2009; Allen et al. 2010). As such, there is great interest in how drought may change in the future, especially at the local scale where adaptation decisions are made. Global Climate Models (GCMs) provide a fundamental starting point for investigating how climate may change in the future, and have shown ability to reproduce surface temperatures over large scales as well as some improvements in simulating global precipitation patterns (Flato et al. 2013). GCM projections suggest that drought will increase across large areas of the globe (Dai 2011, 2013), but GCMs lack skill at simulating climate variations at regional- or local-scales because of their coarse spatial resolution and the increasing importance of internal variability at smaller scales (Deser et al. 2014).

One effective way to counter this is to downscale the GCMs using dynamical downscaling approaches that embed limited area, high-resolution climate models, i.e., Regional Climate Models (RCMs). RCMs are forced by boundary conditions from the GCM, but are free to develop 
their own climate. Because of their smaller domain and higher resolution, RCMs can resolve finer scale physical processes and enhance the representation of land surface characteristics, leading to improved simulation of smaller scales (Dickinson et al. 1989; Giorgi et al. 1994; Wang et al. 2004; Lo et al. 2008; Heikkila et al. 2010; Maraun et al. 2010; Qian et al. 2009; PaiMazumder et al. 2013; Harding et al. 2013). However, these dynamical models remain expensive and therefore limited in their use, especially in terms of running ensembles to make an assessment of the uncertainty from internal variability at local scales.

As an alternative to dynamical downscaling, statistical downscaling can also be an effective way to simulate weather phenomena at local scale (Maraun et al. 2010; Wilby and Wigley 1997; Wilby et al. 1998). A detailed comparison of the advantages and disadvantages of statistical and dynamical downscaling is provided by Fowler et al. (2007). The main advantages of statistical downscaling are that it is computationally efficient and that it can be readily used for any location to derive the local variable of interest (Fowler et al. 2007). The main disadvantage is that statistical downscaling does not include feedback from the climate system, and makes the assumption that the relationship will hold into the future (Fowler et al. 2007).

There are several approaches to statistical downscaling, including "perfect prognosis downscaling" (Maraun et al. 2010), whereby a statistical relationship is developed between observed large-scale predictors and local-scale weather phenomena (e.g., Bruyère et al. 2012). Drought is an extreme that requires skilful prediction of both temperature and precipitation (Bonsal et al. 2012; PaiMazumder and Done 2014), so a logical starting point is to relate local drought to the coarser temperature and precipitation variables from the GCMs; this is often what is done for impact assessments that require finer scale inputs (see Gutmann et al. 2014 and references therein). However, using precipitation as a predictor has been criticized, as regional precipitation is not simulated well by GCMs (Flato et al. 2013). Thus, using precipitation may violate a central tenant of statistical downscaling, which is that the climate model reliably simulates variables from which to downscale (Maraun et al. 2010). As such, one appealing alternative is to use large-scale environmental patterns from GCMs as predictors, which have been shown to be skillfully reproduced (Flato et al. 2013) and have increasing credibility for use in climate change studies (Christensen et al. 2013). For drought, using remote large-scale patterns as predictors is appealing, given the increasing literature on the role of teleconnections on drought and precipitation in the United States (U.S.). For instance, several studies reveal the link between U.S. precipitation and sea surface temperature (SST) anomalies, such as those associated with the El Niño Southern Oscillation (ENSO) (Ting and Wang
1997; Montroy 1997; Montroy et al. 1998). As a specific example, cold SST anomalies in the tropical Pacific helped establish the large-scale conditions for the 1988 drought over the Great Plains (Trenberth et al. 1988; Trenberth and Branstator 1992; Palmer and Brankovic 1989; Namias 1991; Lyon and Dole 1995; Chen and Newman 1998; Hong and Kalnay 2000, 2002). McCabe et al. (2004) found that North Atlantic warming and tropical Pacific cooling helped to explain droughts over the U.S. in 1996 and from 19992002. However, while many of these large-scale phenomenon have been found to be relevant at regional-scales, most stakeholders make decisions at the local level and are only concerned with a relatively small geographic region. As such, it has been found that these large-scale predictors may need to be customized so that they are relevant to a particular location (e.g., Grantz et al. 2005).

The goal of this study is to develop a generalized framework to investigate the use of large-scale environmental patterns as an alternative to precipitation in statistically downscaling to local drought. This responds to increasing calls for generalized approaches that can help to add value and customize climate information for specific decisionmaking contexts (Lemos et al. 2012). The framework has three-steps. In Step 1, two statistical downscaling models are developed: one based on temperature and precipitation and another based on temperature and a remote largescale predictor that serves as a proxy for precipitation. A key component is identifying the large-scale predictor, which is customized for the location of interest. In Step 2, the statistical models are evaluated using NCEP/NCAR Reanalysis data, which serves as a "ground truth" for a climate model, as done in other downscaling studies (e.g., Gutmann et al. 2014; Wilby et al. 2000). Finally, as previously mentioned, an important consideration when predicting at local scales is the increasing importance of internal variability (Deser et al. 2014). As such, a secondary goal of the paper is to examine future changes in light of internal variability, which is accomplished in Step 3 by applying a large ensemble of future GCM projections to the statistical models. The technique is demonstrated for predicting late summer drought in South-central Oklahoma, but the framework is general and could be applied to other areas where local drought is associated with large-scale environmental patterns.

\section{Case study overview}

The framework is demonstrated for South-central Oklahoma, U.S. Climate Division 8 (Fig. 1). Water resources in the division have been the focus of a recent water management controversy (Shriver and Peaden 2009; Lazrus 2016) and are highly influenced by drought conditions (Silvis 


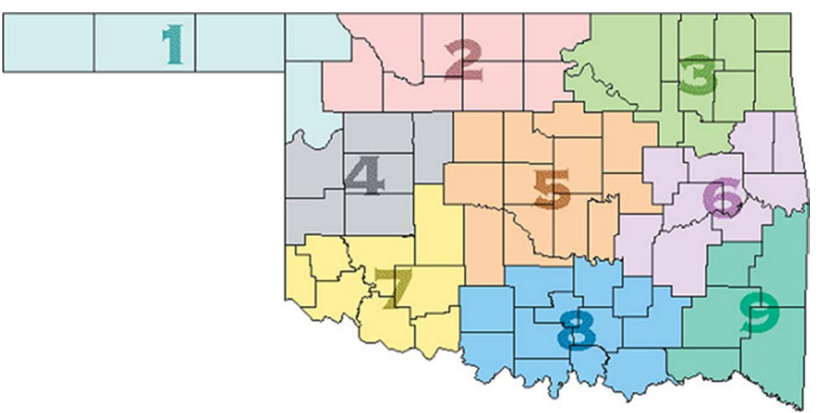

Fig. 1 Oklahoma climate division map, South-central is Climate Division 8. Source Oklahoma climatological survey

et al. 2014). Thus, there is great interest in how drought will change in the future, making it an ideal case study to test a framework that investigates using different predictors for statistical downscaling to local drought.

Although, a variety of indices have been established to characterize droughts (Palmer 1965; Bhalme and Mooley 1980; McKee et al. 1993; Meyer et al. 1993; Phillips and McGregor 1998; Thomas et al. 2014), this study utilizes the Palmer Drought Severity Index (PDSI). The PDSI, originally developed by Palmer (1965), is a well-known measure of meteorological drought that is based on a surface water balance of precipitation, potential evapotranspiration, soil moisture, and runoff. PDSI assesses the cumulative departure from a long-term average and is generally used to characterize long-term drought. Positive PDSI values indicate wetter conditions, while negative PDSI values indicate drier conditions. PDSI has been used to assess historical droughts and future changes over the U.S. (e.g., Dai et al. 1998, 2004; Wells et al. 2004; Van der Schrier et al. 2006; Burke and Brown 2008; Dai 2011). Recently, Bonsal et al. (2012) and PaiMazumder and Done (2014) highlight the importance of considering drought indices, such as PDSI, that consider the combined effects of both precipitation and evaporation changes when assessing future changes to regional-scale drought, especially given the uncertainties and lack of consistency in future precipitation signals. Some shortcomings of PDSI have been identified, especially in terms of how potential evaporation is calculated (Sheffield et al. 2012). Nevertheless, the selection of drought indices for a specific area is often guided by the quantity and quality of available climate data, and historical PDSI data for the U.S. at the climate divisional scale derived from station data are readily available from NOAA's National Climatic Data Center (NCDC).

In this study, we use monthly observed divisional climate data (i.e., precipitation, temperature, and PDSI) for Oklahoma's South-central climate division from NOAA's NCDC (http://www7.ncdc.noaa.gov/CDO/ CDODivisionalSelect.jsp\#) from 1975-2009. We focus specifically on average PDSI in the late summer, JulyAugust-September, in South-central Oklahoma because these are the warmest 3 months of the year (figures not shown), and are therefore likely to cause the worst drought impacts. For instance, July-September has been found to be a season of low recharge for an important groundwater aquifer located in the climate division (Christenson et al. 2011).

\section{The three-step framework}

\subsection{Step 1: develop statistical models}

The first step is to develop the statistical models that can be used to downscale to local drought. Two statistical downscaling models are developed: one based on temperature and precipitation (Sect. 3.1.1, Step 1a) and another based on temperature and a large-scale predictor that serves as a proxy for precipitation (Sect. 3.1.2, Step 1b).

\subsubsection{Step la: drought model with temperature and precipitation}

Despite the widespread usage of PDSI as a drought metric, its calculation relies on a complex algorithm (Alley 1984). For simplicity and transparency, we predict PDSI using a parsimonious statistical regression with two predictors that are readily available and have high explanatory power: temperature and precipitation. However, PDSI is a combination of current conditions and previous PDSI values (Guttman 1998), thus it reflects antecedent moisture conditions. It follows that the best predictors may precede the PDSI season being estimated, and that the most predictive temperature season may be different from the most predictive precipitation season. As such, the PDSI for the season of interest is correlated with temperature to identify the most predictive seasons for temperature. For instance, for this case study, average JulyAugust-September PDSI is correlated with temperature in three-month moving-average windows (e.g., July-AugustSeptember; June-July-August; etc). This is repeated for precipitation. Linear regression identifies the best combination of temperature and precipitation based on $\mathrm{R}^{2}$. This ensures that the precipitation and temperature predictors provide independent information (i.e., both are statistically significant in the linear regression). In addition, root mean-squared error (RMSE), and mean errors (ME) were calculated on the model errors (observed minus predicted). For validation, we tested the predictive skill of these models using cross-validation, whereby (1) one data point is dropped, (2) the model is fit to the remaining data, and (3) the fitted model is used to predict the withheld point. This is repeated for each point in the dataset and $\mathrm{R}^{2}$, RMSE, and ME are computed. 
This regression would be sufficient if we wanted to use precipitation directly from the climate models. However, as previously mentioned, our aim is to compare this with a statistical model that bypasses using precipitation directly in favor of using a large-scale predictor as a proxy for local precipitation. As such, this step identifies the most important season for precipitation, which guides the development of the large-scale predictor in Step $1 b$.

\subsubsection{Step 1b: drought model with temperature and large-scale predictor}

Although some guidance on potential large-scale predictors for precipitation exists (Wilby and Wigley 2000), it is not always apparent $a$ priori what large-scale environmental patterns will be associated with local precipitation. As such, the online NNRP NOAA correlation tool can be used (http://www.esrl.noaa.gov/psd/data/correlation/) to visually examine correlation maps between the precipitation season identified in Sect. 3.1.1 and potential large-scale predictors. For the case study, we examine correlation maps between precipitation and SST and sea level pressure (SLP) based on the period 1975-2009. In addition, composite anomaly maps for SST, SLP, and vector winds for dry and wet years are examined from the NOAA website, http://www.esrl.noaa.gov/psd/cgi-bin/ data/composites/printpage.pl. The composites help with the physical explanation of how large-scale processes may be controlling local precipitation. From this analysis, a representative region that has high statistical correlation and a robust physical explanation is selected. The large-scale variable is spatially averaged over the selected region to create a customized index. From this, a new drought prediction equation is fit using the original temperature predictor and this new customized index in lieu of the original precipitation predictor. The fit is evaluated and validated using the same metrics as the original equation $\left(\mathrm{R}^{2}\right.$, RMSE, and ME).

\subsection{Step 2: evaluate statistical models using NCEP/ NCAR reanalysis data}

The next step is to use the regressions in conjunction with data from the NCEP/NCAR Reanalysis Project (NNRP; Kalnay et al. 1996), as NNRP temperature and precipitation data serve as a proxy for climate model data. NNRP is a global reanalysis with horizontal resolution approximately $1.9^{\circ} \times 1.9^{\circ}$ and 28 vertical levels. The reanalysis is accomplished using an atmospheric model comparable to those used in climate models running in continuous data assimilation mode. Both statistical models are driven with data extracted from NNRP to provide a "best case" analog for a climate model.

\subsection{Step 3: apply GCM projections to statistical models}

In Step 3, we use the statistical models developed in Step 1 with predictor data from GCM projections to examine future changes. However, given the importance of internal variability at smaller scales (Deser et al. 2014), future changes are assessed in light of internal variability by using a large ensemble of future projections. We use precipitation, temperature, and large-scale data from existing simulations of a large ensemble of the Community Earth System Model (CESM-LE; Kay et al. 2015). CESM-LE is a 30-member ensemble, run under the Representative Concentration Pathway 8.5 (RCP 8.5) to the year 2080. In this study we assume that the model bias is stationary in time (Buonomo et al. 2007; Done et al. 2013; PaiMazumder et al. 2013; PaiMazumder and Done 2014). We examine changes to PDSI by looking at future anomalies, i.e., we calculate each ensemble member's mean PDSI for the control period (1975-2005) and subtract that from each member.

\section{Results}

\subsection{Statistical drought models}

The first step uses the observational dataset to develop a statistical model to estimate late summer (July-AugustSeptember) PDSI. The best predictive temperature season is identified to be late summer, i.e., July-August-September $(\mathrm{r}=-0.74)$, and the best predictive precipitation season is identified to be late spring, i.e., April-May-June $(\mathrm{r}=0.70)$. These predictors are physically consistent, given the fact that in South-central Oklahoma, July-August-September are the hottest months (figures not shown), and that April-May-June make up the wet season that corresponds to a season of high recharge for an important aquifer in the climate division (Christenson et al. 2011). When these two predictors are fit in a linear regression, $74 \%$ of the variance is explained ( $68 \%$ in cross-validation mode) and both predictors are statistically significant (Table 1 ). The mean error (ME) is 0.00 , indicating that the regression is not biased towards wet or dry, and the root mean square error (RMSE) is 1.2. Diagnostics show that the underlying linear regression assumptions are reasonable (figures not shown). However, as previously mentioned, in this study we want to explore using a customized large-scale index in lieu of using precipitation directly.

Using the NNRP NOAA correlation tool, large-scale patterns that correlate with observed April-May-June precipitation are identified. We examine SST and SLP correlation maps, and find SLP patterns that are statistically significant and physically robust. Two prominent features are 
Table 1 Coefficients and fit statistics to predict July-August-September Palmer Drought Severity Index for model including precipitation (Model 1) and for model including large-scale proxy (Model 2)

\begin{tabular}{lll}
\hline \multicolumn{2}{c}{ Model 1 } & \multicolumn{1}{l}{ Model 2} \\
\hline Coefficients (Standard & Errors $)$ & \\
Intercept & $24.501(5.3212)$ & $1521.7(469.02)$ \\
TMP.JAS $\left({ }^{\circ} \mathrm{C}\right)$ & $-1.0595(0.19051)$ & $-1.1701(0.23061)$ \\
PCP.AMJ (mm) & $0.035613(0.0064829)$ & \\
SLP.AMJ (mb) & & $-1.4671(0.46352)$ \\
Fit (validation) statistics & \\
p value & $1.00 \mathrm{E}-09$ & $2.90 \mathrm{E}-07$ \\
$\mathrm{R}^{2}\left(\mathrm{R}^{2} \mathrm{xval}\right)$ & $0.736(0.683)$ & $0.610(0.543)$ \\
RMSE (RMSE_xval) & $1.15(1.27)$ & $1.40(1.53)$ \\
ME (ME_xval) & $0.00(0.02)$ & $0.00(0.01)$ \\
\hline
\end{tabular}

TMP.JAS, average July-August-September temperature in degrees Celsius $\left({ }^{\circ} \mathrm{C}\right)$; SLP.AMJ, average April-May-June sea level pressure in hectopascals (hPa); PCP.AMJ, average April-May-June precipitation in millimeters (mm); RMSE, root mean square error; ME, mean error; xval, cross-validated

notable (Fig. 2): an area of negative correlation in the eastern North Pacific and an area of positive correlation over much of North America. To understand these, we consider the composite anomalies for SLP as well as 500 Hectopascals $(\mathrm{hPa})$ vector winds for the top six wet and dry years (Fig. 3); these maps show a similar pattern to the SLP correlation map, but with alternating signs for the wet and dry years. The composite patterns in Fig. 3 suggest an underlying energy dispersion process, whereby the anomalous high and low SLP areas alternate along a great circle. This has some similarities to the Pacific North American (PNA) teleconnection pattern (Wallace and Gutzler 1981) a potential relationship that is being examined in a separate study. To create the large-scale index, we select the region of negative correlation over the eastern North Pacific (dashed box in Fig. 3; 5N-30N, 160W-120W) based on the understanding that both regions are based on the same physical process. An index based on the average SLP over the box in Fig. 2 and precipitation for South-central Oklahoma show an inverse relationship $(\mathrm{r}=-0.45)$, where increasing SLP corresponds to decreasing local precipitation (Fig. 4).

The composite maps are also consistent with known patterns contributing to wet and dry years in the Oklahoma region. Wet years are characterized by anomalous low pressure and cyclonic mid level flow over the central North Pacific, with a jet of moist tropical air extending into the southern Plains combining with increased moisture from the Gulf of Mexico. These are conditions previously analyzed to be associated with heavy spring and summer rainfall over the southern Plains (e.g., Dirmeyer and Kinter 2010). For dry years, the central North Pacific is dominated by anomalous ridging, with troughing over Alaska and Canada. The result is to cut off tropical moisture from the eastern North Pacific with generally continental air and dry conditions over the Plains. This anticyclonic (clockwise in the Northern hemisphere) flow is consistent with conditions of the 1988 drought over the Midwest US (Namias 1991).

SST anomalies show an interesting relationship with ENSO (Fig. 5). The dry-year composite pattern resembles
Fig. 2 Correlation map between South-central Oklahoma average April-May-June precipitation and April-MayJune sea level pressure (SLP). Dashed box is area from which average SLP is calculated to develop the large-scale index (i.e., $5 \mathrm{~N}-30 \mathrm{~N}, 160 \mathrm{~W}-120 \mathrm{~W}$ )

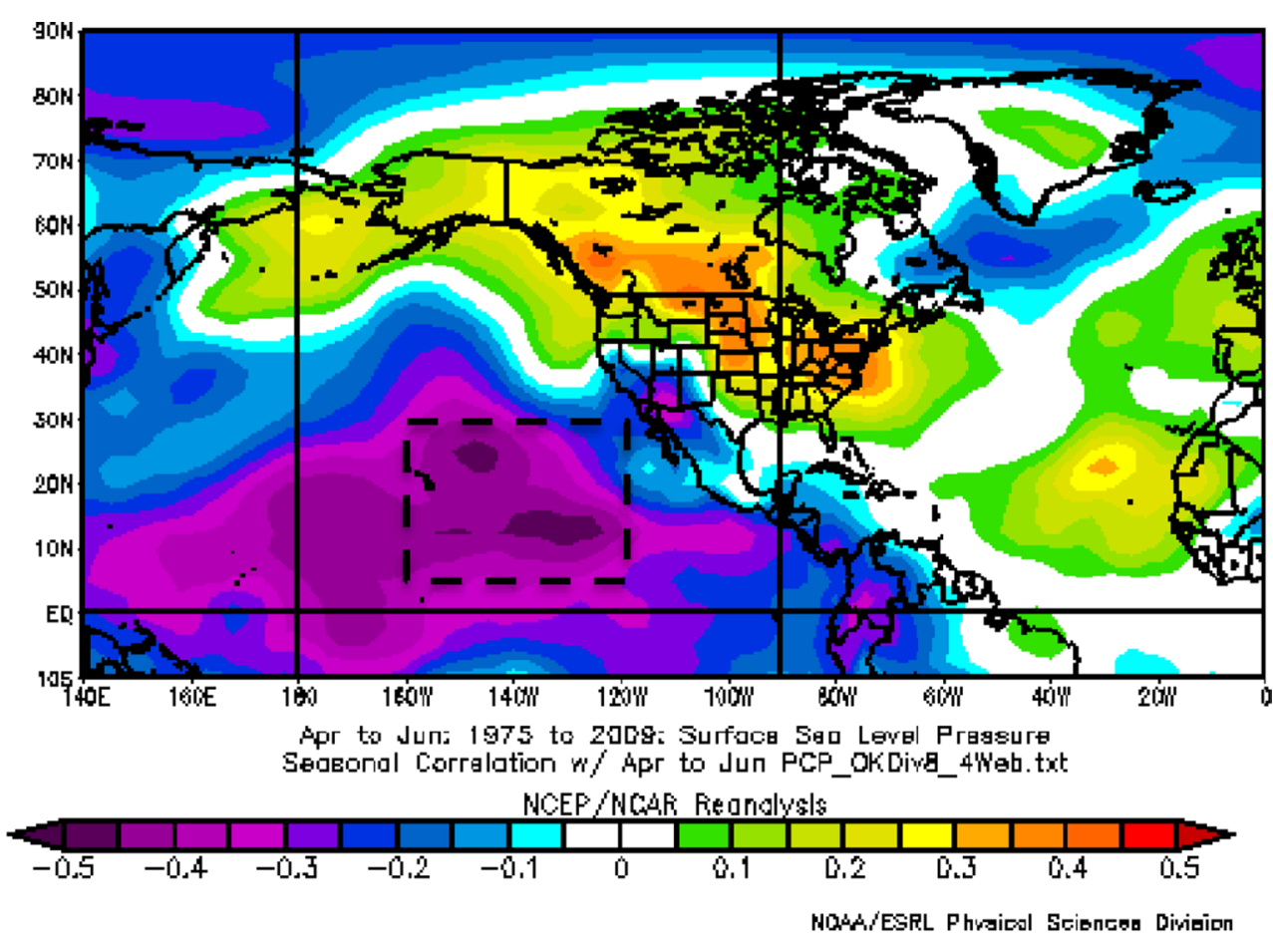



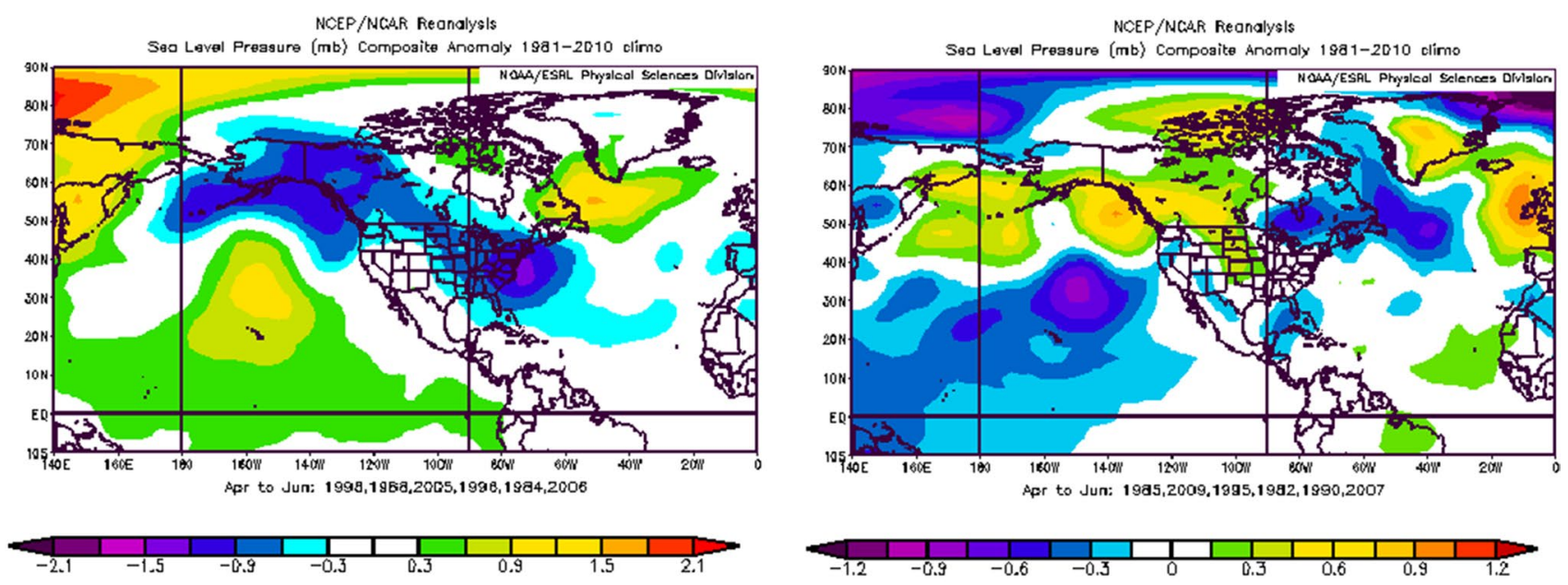

NCEP/NGA.R Reanalysls
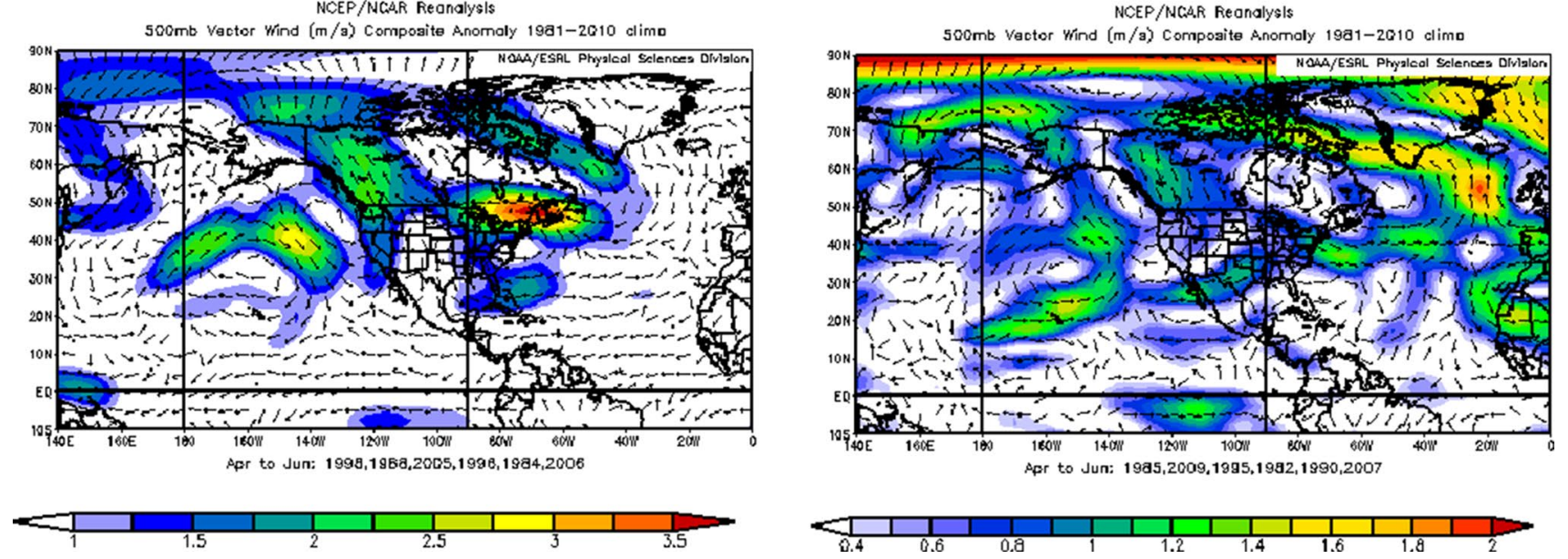

Fig. 3 Composite anomaly maps for dry (left) and wet (right) years for sea level pressure (top) and $500 \mathrm{hPa}$ vector winds (bottom)

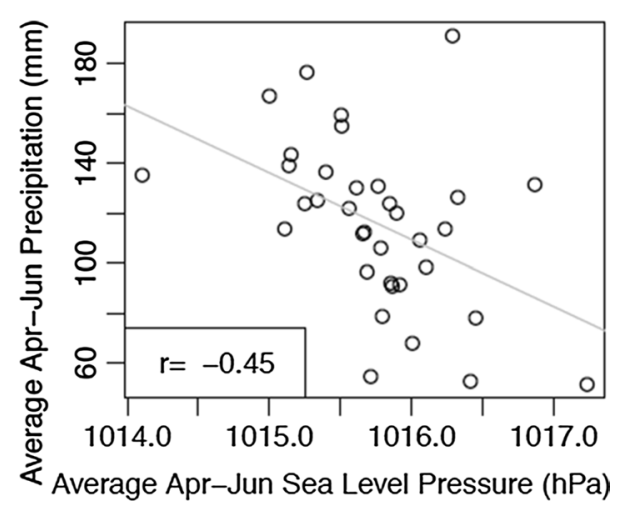

Fig. 4 Scatterplot of sea level pressure (SLP) index and precipitation with linear correlation $(r)=-0.45$

the Nino 3 index (i.e., Eastern Tropical Pacific SSTs from $5 \mathrm{~N}-5 \mathrm{~S}, 150 \mathrm{~W}-90 \mathrm{~W}$ ), whereas the wet-year composite pattern is more like the Nino $1+2$ index (i.e., Extreme
Eastern Tropical Pacific SSTs from 0-10S, 90W-80W). This changeover has similarities to the Modoki pattern (Ashok et al. 2007), which has been associated with similar wet-dry periods in the western United States to those found in this composite (Weng et al. 2007). Because the SST composites do not have an alternating pattern in terms of sign like SLP, there was not a common area from which an SST index could be developed. Nevertheless, this suggests that the SLP and vector wind patterns have some relationship to the ENSO/Modoki phenomenon; this is consistent with mechanistic experiments showing that SSTs combined with favorable atmospheric circulations to establish the 1988 drought over Oklahoma (Hong and Kalnay 2000, 2002). However, it is not surprising that when we tested the standard ENSO indices with late spring precipitation we did not find any statistically significant correlations. This shows a key limitation of analyses that only test the standard ENSO indices as explanatory variables. More details on this follow in the discussion. 

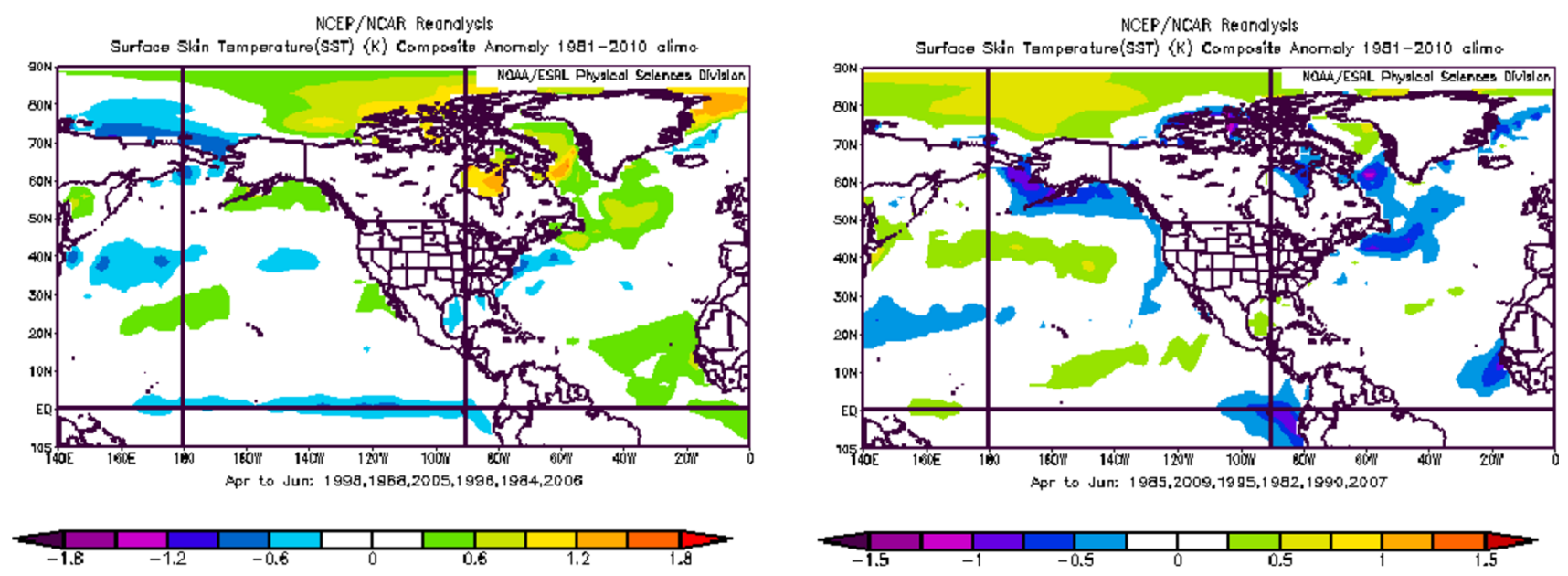

Fig. 5 Composite anomaly sea surface temperature (SST) maps for dry (left) and wet (right) years
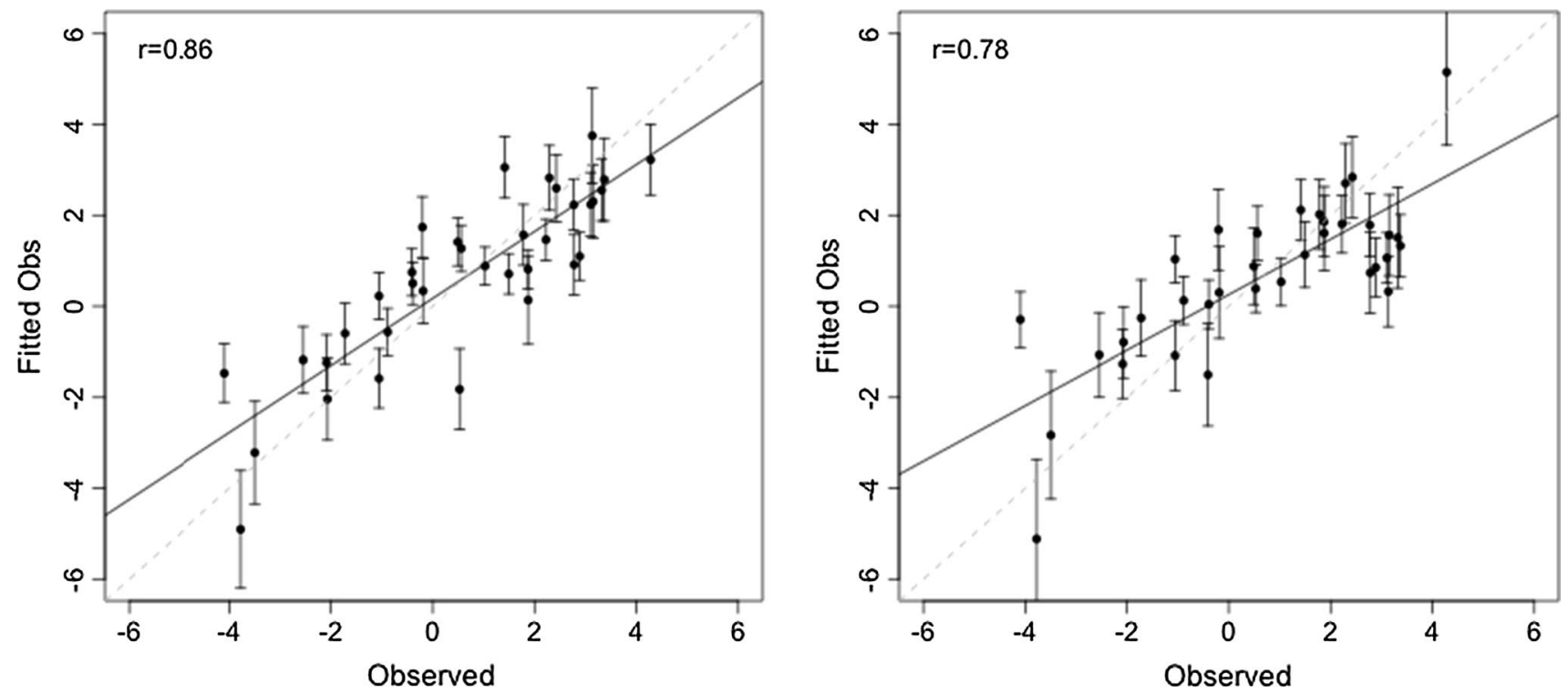

Fig. 6 Observed versus fitted predictions and $95 \%$ confidence intervals for regression that includes precipitation (left) and SLP index (right) using fitted observations. Solid line is best-fit line and dashed line is 1-to-1 line

When the observed temperature and the customized SLP index are used as predictors, the linear regression explains $61 \%$ of the variance (54\% in cross-validation model) and both predictors are significant (Table 1). As expected, there is less $(13 \%)$ variance explained than in the regression that includes observed precipitation. The mean error (ME) is 0.00 , indicating that the regression is not biased towards wet or dry, and the root mean square error (RMSE) is 1.4. Diagnostics show that the underlying linear regression assumptions are reasonable (figures not shown).

Figure 6 shows the observed versus fitted predictions and $95 \%$ confidence intervals for both regressions; the clustering of the fitted values around the 1-to-1 line indicates that the regressions are doing a good job of capturing the observations. This provides confidence that the regressions are skillful and capture the main processes governing late summer drought in South-central Oklahoma.

\subsection{Evaluation with NNRP}

The next step is to evaluate the regressions with NNRP temperature and precipitation data as a proxy for climate model data. All climate models suffer from some sort of bias, so the first step is to examine the biases for 
Fig. 7 Observed versus NNRP average July-August-September temperature (TMP.JAS; left) and average April-May-June precipitation (PCP.AMJ right). Solid line is 1-to-1 line

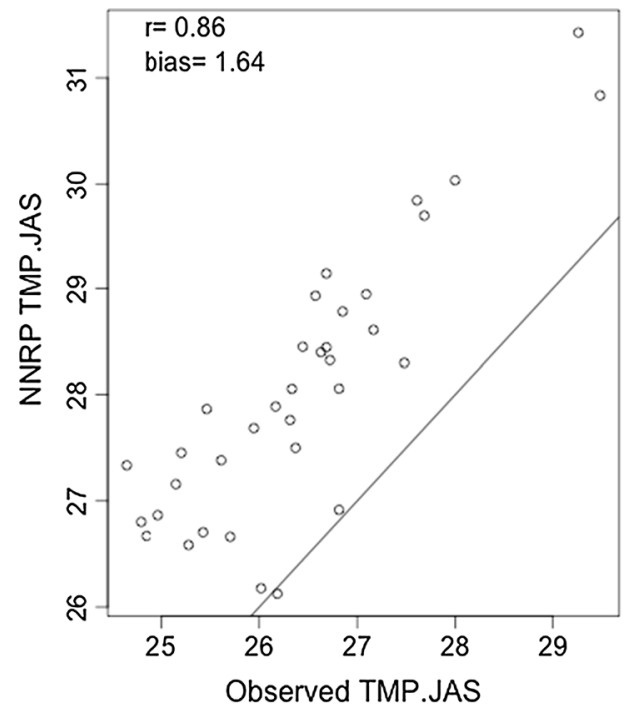

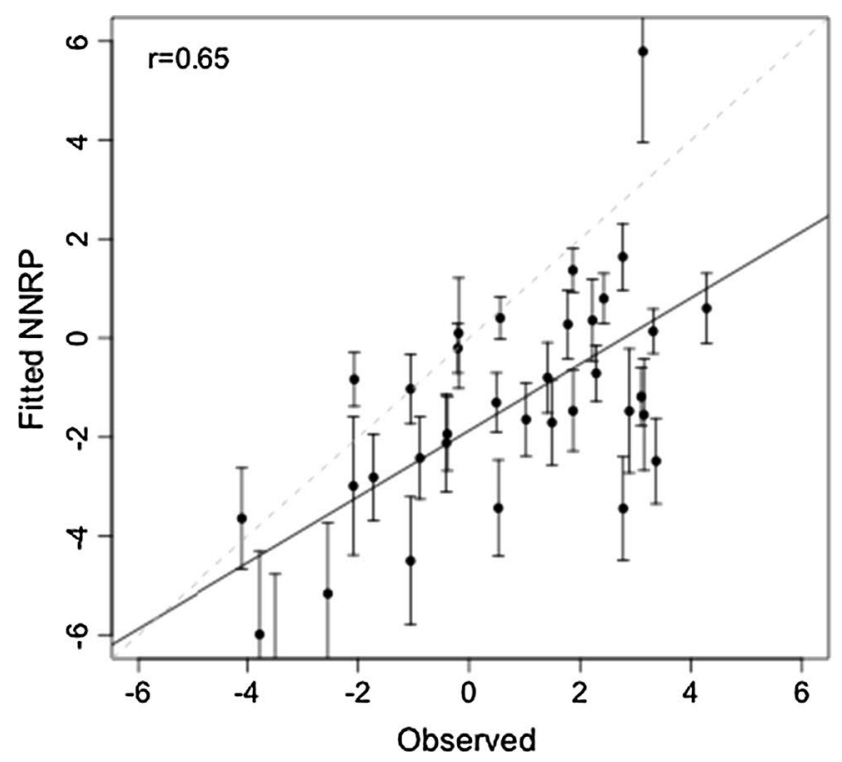

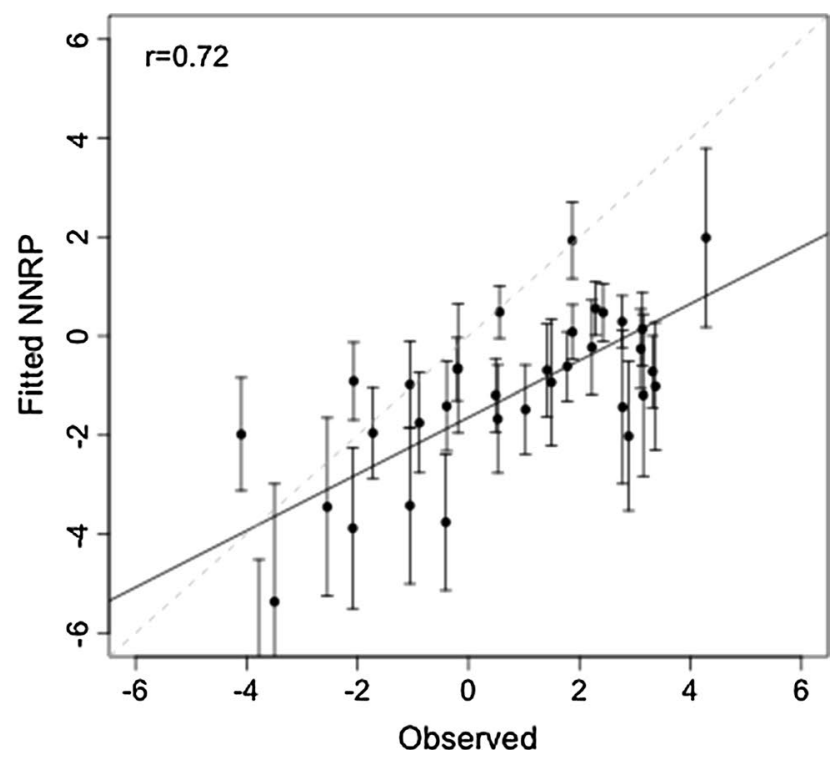

Fig. 8 Observed versus fitted predictions and $95 \%$ confidence intervals for regression that includes precipitation (left) and SLP index (right) using NNRP data. Solid line is best-fit line and dashed line is 1-to-1 line

temperature and precipitation from NNRP. Temperature shows a systematic warm bias (Fig. 7), but relatively high correlation (0.86). Precipitation shows a slight dry bias (Fig. 7), and a relatively lower correlation (0.63). As we would expect, using the NNRP data to drive the statistical models results in lower correlations and a dry bias (Fig. 8). However, both statistical models perform similarly, with the SLP model having a slightly higher correlation than the precipitation model $(r=0.72$ versus $r=0.65$ ). This suggests that the models are comparable, and provides confidence in using the customized SLP index as a predictor.

\subsection{Assessment of future changes in light of internal variability}

Using the CESM-LE with both statistical models indicates that on average, drought is likely to increase considerably in South-central Oklahoma (Fig. 9). For the period of 2020-2049, the statistical model using SLP results in an average PDSI anomaly of -2.7 . Similarly, the statistical model using precipitation gives an average drought anomaly of -2.2 . This arises mainly from warmer conditions; the SLP decrease is indicative of slightly wetter conditions, but these are not sufficient to counteract the increase 

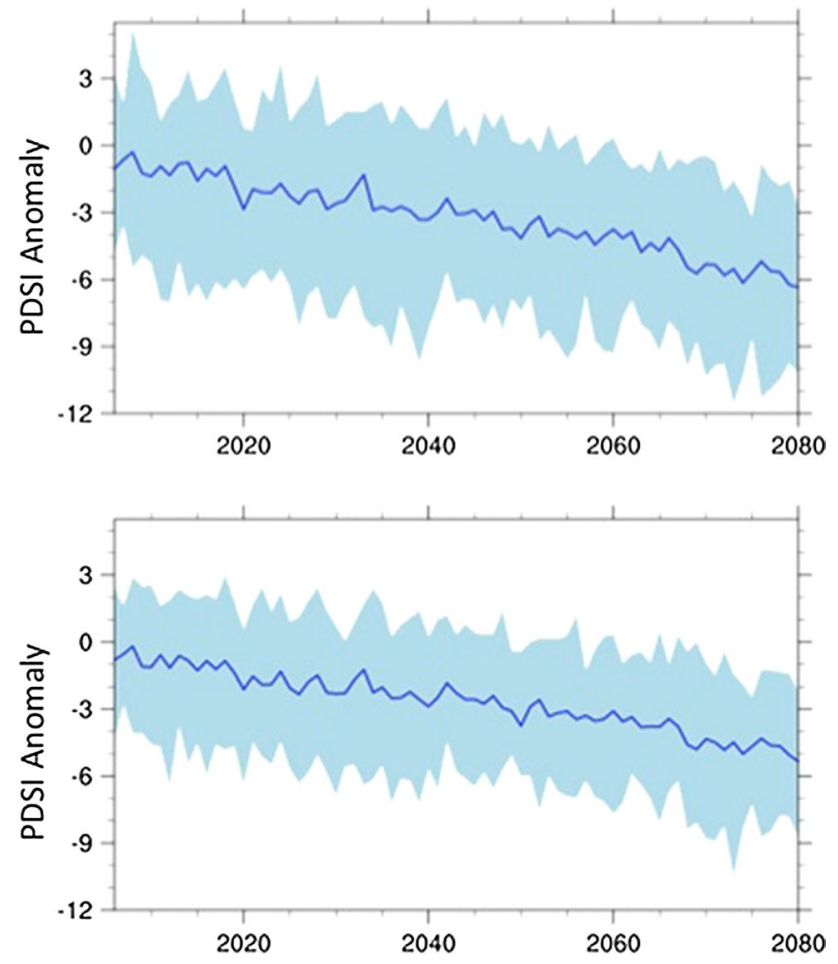

Fig. 9 Palmer Drought Severity Index (PDSI) anomalies from the CESM-LE using the statistical model with SLP (top) and precipitation (bottom). Solid line is ensemble mean, and blue shaded area indicates the ensemble spread

in temperature. It is the same with precipitation, where the increase is not great enough to offset the temperature increase. However, there is a large range of internal variability: the mean maximum from the 2020-2049 period is actually positive, 1.4 and 1.1 for the SLP and precipitation models, respectively. This indicates that despite a decreasing trend, there may still be wet periods. But perhaps more noteworthy is the fact the average minimum from the 2020-2049 period is -7.2 and -5.8 , which would indicate substantially drier periods. The similarity of the results provides some confidence in the projections, but shows that local PDSI is more sensitive to internal variability than it is to the choice of predictor (i.e., precipitation versus SLP).

\section{Discussion}

A novel part of this paper is the development of a customized large-scale index to serve as a predictor of local PDSI, which is developed by visually examining the linkage between local precipitation and large-scale environmental patterns (e.g., SLP) and selecting a region with high statistical correlation and a physically robust explanation. We do note that selection of the index region is somewhat subjective. We select a relatively large region because of the coarse resolution of the GCMs and a sensitivity analysis showed that using a smaller sub-region did not change the correlation (figures not shown). The key is that the box is customizable to the local variable of interest, rather than static. This is not to say that the large-scale predictor identified does not have skill at predicting phenomena in the larger region, but the key is that the large-scale index can be tailored to the location and season of interest. Standard indices previously have been developed that are linked to particular regions of the ocean (e.g., Nino 3 averages SSTs over $5 \mathrm{~N}-5 \mathrm{~S}, 150 \mathrm{~W}-90 \mathrm{~W}$ ), but a slight shift in the pattern can cause a low correlation that can belie a true connection. In our study, the SST composites show that ENSO is related to precipitation anomalies in South-central Oklahoma (Fig. 6), but correlations with the standard indices are low (results not shown). As such, this study shows that developing customized indices from large-scale patterns is a flexible and powerful approach for identifying explanatory variables for local prediction. Further, it can identify connections that may not have been apparent a priori. We note that similar approaches have shown promise for streamflow forecasting as well (Grantz et al. 2005; Regonda et al. 2006; Bracken et al. 2010).

Many downscaling techniques essentially rescale coarse precipitation to local scales for impact assessments (see Gutmann et al. 2014 and references therein), but may be problematic because of the uncertainty in future precipitation projections (Collins et al. 2013). The advantages of using large-scale predictors are that (1) GCMs have shown skill and ability to reproduce large-scale patterns, (2) largescale predictors have broad influence across a variety of impacts of interest, and (3) diagnosing the bias is more tractable for large-scale features than it is for diagnosing the cause of precipitation errors in every region of interest. The main disadvantage is that it assumes that the relationship will be stationary into the future (Wilby et al. 2004).

The framework is demonstrated for late summer PDSI in South-central Oklahoma, but we note that the steps are general and can be modified to investigate the use of large-scale patterns as an alternative to precipitation for other locations. To demonstrate this, we provide results for another case study location, Southwestern Montana, in the Electronic Supplemental Material. Here we find that $500 \mathrm{mb}$ geopotential height (GP500) provides a suitable predictor (see Electronic Supplemental Material). However, we find that the GP500 does not perform as well as using model precipitation directly for downscaling to local drought. We thus demonstrate how our generalized framework can be used to investigate the use of large-scale patterns as an alternative to precipitation for any location, and we provide examples of where these patterns were better and worse than using model precipitation directly in predicting local drought. Further, our aim was to develop a 
parsimonious model using climate information, but we note that other local variables could be considered to increase the variance explained. However, observational data of other relevant local variables, such as local orography, land cover type, soil moisture, etc., may not be readily available. In addition, we use linear regression, but there are other statistical frameworks that can include covariates that have been used successfully to predict climate impacts. For example, Generalized Linear Modeling (McCullagh and Nelder 1989) is a more general framework that has been used to predict a suite of different hydrologic attributes (i.e., discrete, categorical, etc.) (e.g., Towler et al. 2013).

\section{Conclusions}

This paper develops a three-step framework for investigating the use of large-scale environmental patterns as an alternative for precipitation in statistically downscaling to local drought. A novel contribution is in identifying a largescale predictor that is customized to be relevant to a particular location. When we apply the framework, we find that using precipitation in the statistical regression explains more of the variance when predicting drought with observations, but when we use NNRP as a surrogate for a climate model, we find that using the customized SLP index explains slightly more variance $(r=0.72$ vs $r=0.65)$. When applied to a large ensemble of future projections, both statistical models showed similar drying patterns for South-central Oklahoma, adding some confidence to this signal. However, the results also showed that future PDSI is more sensitive to internal variability than to the selection of the predictor (i.e., precipitation versus SLP).

This example demonstrates two things. First, if the customized large-scale index performs comparably (or better) than precipitation directly when evaluated using NNRP data, then it is an appealing predictor choice to use with future projections. This is because large-scale environmental patterns are increasingly well simulated by GCMs, thus boosting the credibility of projected future change (Christensen et al. 2013). Secondly, when statistically downscaling to local scales, it is critical to consider internal variability, as it may be more important than predictor selection.

Given the importance of water resources and drought impacts, it is critical to investigate new tools that can help inform local adaptation efforts. As an extension, we are performing a complementary study that involves combining output from this work with how people perceive drought risks to inform water management in the region (Towler et al. 2016).

Acknowledgments This work is partially supported by NSF EASM Grants 1048841 and 1048829 . NCAR is sponsored by the National
Science Foundation. Figures 2, 3, and 5 provided by the NOAAESRL Physical Sciences Division, Boulder Colorado from their Web site at http://www.esrl.noaa.gov/psd/. Thanks to Heather Lazrus and Tom Galarneau for useful discussions.

Open Access This article is distributed under the terms of the Creative Commons Attribution 4.0 International License (http://creativecommons.org/licenses/by/4.0/), which permits unrestricted use, distribution, and reproduction in any medium, provided you give appropriate credit to the original author(s) and the source, provide a link to the Creative Commons license, and indicate if changes were made.

\section{References}

Allen CD, Macalady AK, Chenchouni H, Bachelet D, McDowell $\mathrm{N}$ et al (2010) A global overview of drought and heatinduced tree mortality reveals emerging climate change risks for forests. For Ecol Manag 259(4):660-684. doi:10.1016/j. foreco.2009.09.001

Alley WM (1984) The Palmer drought severity index: limitations and assumptions. J Clim Appl Meteorol 23(7):1100-1109

Ashok K, Behera SK, Rao SA, Weng H, Yamagata T (2007) El Niño Modoki and its possible teleconnection. J Geophys Res. doi:10.1 029/2006JC003798

Bhalme HN, Mooley DA (1980) Large-scale droughts/floods and monsoon circulation. Mon Wea Rev 108:1197-1211. doi:10.1175/1520-0493(1980)108<1197:LSDAMC >2.0.CO;2

Bonsal BR, Aider R, Gachon P, Lapp S (2012) An assessment of Canadian prairie drought: past, present, and future. Clim Dyn. doi:10.1007/s00382-012-1422-0

Bracken C, Rajagopalan B, Prairie J (2010) A multisite seasonal ensemble streamflow forecasting technique. Water Resour Res 46:W03532. doi:10.1029/2009WR007965

Bruyère CL, Holland GJ, Towler E (2012) Investigating the use of a Genesis Potential Index for tropical cyclones in the North Atlantic basin. J Climate 25(24):8611-8626. doi:10.1175/ JCLI-D-11-00619.1

Buonomo E, Jones RG, Huntingford C, Hannaford J (2007) On the robustness of changes in extreme precipitation over Europe from two high resolution climate change simulations. Q J R Meteorol Soc 133:65-81

Burke EJ, Brown SJ (2008) Evaluating uncertainties in the projection of future drought. J Hydrometeorol 9:292-299. doi:10.1175/200 7JHM929.1

Chen P, Newman M (1998) Rossby wave propagation and the rapid development of upper-level anomalous anticyclones during the 1988 U.S. drought. J Clim 11:2491-2504

Christensen JH, Krishna Kumar K, Aldrian E, An S-I, Cavalcanti IFA et al (2013) Climate phenomena and their relevance for future regional climate change. In: Stocker, TF, Qin D, Plattner G-K, Tignor M, Allen SK, Boschung J, Nauels A, Xia Y, Bex V, Midgley PM (eds.), Climate change 2013: the physical science basis. Contribution of working group I to the fifth assessment report of the intergovernmental panel on climate change. Cambridge University Press, Cambridge, United Kingdom and New York, NY, USA

Christenson S, Osborn NI, Neel CR, Faith JR, Blome CD, Puckette J, Pantea MP (2011) Hydrogeology and Simulation of groundwater flow in the Arbuckle-Simpson Aquifer, South-Central Oklahoma. Scientific Investigations Report 2011-5029

Collins M, Knutti R, Arblaster J, Dufresne J-L, Fichefet T et al (2013) Long-term climate change: projections, commitments 
and irreversibility. In: Stocker TF, Qin D, Plattner G-K, Tignor M, Allen SK, Boschung J, Nauels A, Xia Y, Bex V, Midgley PM (eds), Climate Change 2013: The Physical Science Basis. Contribution of Working Group I to the Fifth Assessment Report of the Intergovernmental Panel on Climate Change. Cambridge University Press, Cambridge, United Kingdom and New York, NY, USA

Dai A (2011) Drought under global warming: a review. Wiley Interdiscip Rev Clim Change 2(1):45-65. doi:10.1002/wcc.81

Dai A (2013) Increasing drought under global warming in observations and models. Nat Clim Change 3:52-58. doi:10.1038/nclimate1633

Dai A, Trenberth KE, Karl TR (1998) Global variations in droughts and wet spells: 1900-1995. Geophys Res Lett 25:3367-3370

Dai A, Trenberth KE, Qian T (2004) A global dataset of Palmer Drought Severity Index for 1870-2002: relationship with soil moisture and effects of surface warming. J Hydrometeorol 5:1117-1130

Deser C, Phillips AS, Alexander MA, Smoliak BV (2014) Projecting North American climate over the next 50 years: uncertainty due to internal variability. J Clim 27:2271-2296. doi:10.1175/ JCLI-D-13-00451.1

Dickinson RE, Errico RM, Giorgi F, Bates GT (1989) A regional climate model for the western United States. Clim Change 15:383-422

Dirmeyer PA, Kinter JL (2010) Floods over the U.S. Midwest: a regional water cycle perspective. J Hydrometeorol 11:11721181. doi:10.1175/2010JHM1196.1

Done JM, Holland GJ, Bruyère CL, Leung LR, Suzuki-Parker A (2013) Modeling high-impact weather and climate: lessons from a tropical cyclone perspective. Clim Change. doi:10.1007/ s10584-013-0954-6

Eriyagama N, Smakhtin V, Gamage N (2009) Mapping drought patterns and impacts: a global perspective. International Water Management Institute (IWMI), Colombo

Flato G, Marotzke J, Abiodun B, Braconnot P, Chou SC et al (2013) Evaluation of climate models. In: Stocker TF, Qin D, Plattner G-K, Tignor M, Allen SK, Boschung J, Nauels A, Xia Y, Bex V, Midgley PM (eds), Climate change 2013: the physical science basis. Contribution of working group I to the fifth assessment report of the Intergovernmental Panel on Climate Change. Cambridge University Press, Cambridge, United Kingdom and New York, NY, USA

Fowler H, Blenkinsop S, Tebaldi C (2007) Linking climate change modelling to impacts studies: recent advances in downscaling techniques for hydrological modelling. Int J Climatol 27:15471578. doi:10.1002/joc

Giorgi F, Brodeur CS, Bates CT (1994) Regional climate change scenarios over the United States produced with a nested regional climate model. J Clim 7:357-399

Grantz K, Rajagopalan B, Clark M, Zagona E (2005) A technique for incorporating large-scale climate information in basin-scale ensemble streamflow forecasts. Water Resour Res 41:W10410. doi:10.1029/2004WR003467

Gutmann E, Pruitt T, Clark M, Brekke L, Arnold JR, Raff D, Rasmussen R (2014) An intercomparison of statistical downscaling methods used for water resource assessments in the United States. Water Resour Res. doi:10.1002/2014WR015559

Guttman NB (1998) Comparing the Palmer drought index and the standardized precipitation index. J Am Water Res Assoc 34:113-121

Harding KJ, Snyder PK, Liess S (2013) Use of dynamical downscaling to improve the simulation of Central U.S. warm season precipitation in CMIP5 models. J Geophys Res Atmos 118(22):12522-12536. doi:10.1002/2013JD019994

Heikkila U, Sandvik A, Sorteberg A (2010) Dynamical downscaling of ERA-40 in complex terrain using the WRF regional climate model. Clim Dyn 37:1551-1564. doi:10.1007/s00382-010-0928-6
Hong SY, Kalnay E (2000) Role of SST and soil-moisture feedback in the 1998 Oklahoma-Texas drought. Nature 408:842-844

Hong SY, Kalnay E (2002) The 1998 Oklahoma-Texas drought: mechanistic experiment with NECP global and regional models. J Climate 15:945-963

Kalnay E, Kanamitsu M, Kistler R, Collins W, Deaven D et al (1996) The NCEP/NCAR 40-year reanalysis project. Bull Am Meteorol Soc 77:437-477

Kay JE, Deser C, Phillips A et al (2015) The community earth system model (CESM) large ensemble project: a community resource for studying climate change in the presence of internal climate variability. Bull Amer Meteorol Soc. doi:10.1175/ BAMS-D-13-00255.1

Lazrus H (2016) "Drought is a relative term": Drought risk perceptions and water management preferences among diverse community members in Oklahoma, USA. Hum Ecol (in review)

Lemos MC, Kirchhoff CJ, Ramprasad V (2012) Narrowing the climate information usability gap. Nature Clim Change 2(11):789794. doi:10.1038/nclimate1614

Lo JC, Yang ZL, Pielke RA Sr (2008) Assessment of three dynamical climate downscaling methods using the Weather Research and Forecasting (WRF) model. J Geophys Res 113:D09112. doi:10. 1029/2007JD009216

Lyon B, Dole RM (1995) A diagnostic comparison of the 1980 and 1988 US summer heat wave-droughts. J Clim 8(6):1658-1675

Maraun D, Wetterhall F, Ireson AM et al (2010) Precipitation downscaling under climate change: Recent developments to bridge the gap between dynamical models and the end user. Rev Geophys 48:Rg3003. doi:10.1029/2009rg000314

McCabe GJ, Palecki MA, Betancourt JL (2004) Pacific and Atlantic Ocean influences on multidecadal drought frequency in the United States. Proc Natl Acad Sci USA. doi:10.1073/pnas.0306738101

McCullagh P, Nelder JA (1989) Generalized linear models. Chapman and Hall, London

McKee TB, Doesken NJ, Kleist J (1993) The relationship of drought frequency and duration to time scales. In: Preprints, 8th conference on applied climatology. American Meteorological Society, Anaheim, California, pp 179-184

Meyer SJ, Hubbard KG, Wilhite DA (1993) A crop-specific drought index for corn: I. Model development and validation. Agron J 86:388-395

Montroy DL (1997) Linear relation of central and eastern North American precipitation to tropical Pacific sea surface temperature anomalies. J Clim 10:531-548

Montroy DL, Richman MB, Lamb PJ (1998) Observed nonlinearities of monthly teleconnections between tropical Pacific sea surface temperature anomalies and central and eastern North American precipitation. J Clim 11:1812-1835

Namias J (1991) Spring and summer 1988 drought over the contiguous United States - causes and prediction. J Clim 4:54-65

PaiMazumder D, Done JM (2014) Uncertainties to long-term droughts characteristics over Canadian Prairies as simulated by the Canadian RCM. Clim Res. doi:10.3354/cr01196

PaiMazumder D, Sushama L, Laprise R, Khaliq N, Sauchyn D (2013) Canadian RCM projected changes to short- and long-term drought characteristics over the Canadian Prairies. Int J Climatol. doi:10.1002/joc. 3521

Palmer WC (1965) Meteorological drought. Res Paper No 45. Weather Bureau, Washington, DC

Palmer TN, Brankovic C (1989) The 1988 United States drought linked to anomalous sea surface temperature. Nature 338:54-57

Phillips ID, McGregor GR (1998) The utility of a drought index for assessing the drought hazard in Devon and Cornwall, South West England. Meteorol Appl 5:359-372

Qian Y, Ghan SJ, Leung LR (2009) Downscaling hydroclimatic changes over the Western U.S. Based on CAM subgrid scheme 
and WRF regional climate simulations. Int J Climatol 30(5):675693. doi:10.1002/joc. 1928

Regonda SK, Rajagopalan B, Clark M, Zagona E (2006) A multimodel ensemble forecast framework: application to spring seasonal flows in the Gunnison River Basin. Water Resour Res 42:W09404. doi:10.1029/2005WR004653

Sheffield J, Wood EF, Roderick ML (2012) Little change in global drought over the past 60 years. Nature 491(7424):435-438. doi:10.1038/nature 11575

Shriver TE, Peaden C (2009) Frame disputes in a natural resource controversy: the case of the Arbuckle Simpson Aquifer in southcentral Oklahoma. Soc Nat Resour 22:143-157

Silvis V, McPherson RA, Lazrus H (2014) Climatology of the Arbuckle-Simpson Aquifer region: a report of the water decisions for sustainability of the Arbuckle-Simpson project. NCAR Technical Note NCAR/TN-510+STR. doi:10.5065/D6Z31WN9

Thomas AC, Reager JT, Famiglietti JS, Rodell M (2014) A GRACEbased water storage deficit approach for hydrological drought characterization. Geophys Res Lett 41:1537-1545. doi:10.1002/ 2014GL059323

Ting M, Wang H (1997) Summertime U.S. precipitation variability and its relation to Pacific sea surface temperature. J Climate 10:1853-1873

Towler E, Roberts M, Rajagopalan B, Sojda R (2013) Incorporating probabilistic seasonal climate forecasts into river management using a risk-based framework. Water Resour Res 49:4997-5008. doi: $10.1002 /$ wrcr. 20378

Towler E, Lazrus H, PaiMazumder D (2016) Characterizing drought risks and implications for water management under climate change. NCAR Technical Note (in review)

Trenberth KE, Branstator GW (1992) Issues in establishing causes of the 1988 drought over North America. J Clim 5:159-172

Trenberth KE, Branstator GW, Arkin PA (1988) Origins of the 1988 North American drought. Science 242:1640-1645
Van Der Schrier G, Briffa KR, Jones PD, Osborn TJ (2006) Summer moisture variability across Europe. J Clim 19:2818-2834

Wallace JM, Gutzler DS (1981) Teleconnections in the geopotential height field during the Northern Hemisphere Winter. Mon Weather Rev 109:784-812

Wang Y, Leung LR, McGregor JL, Lee DK, Wang WC, Ding Y, Kimura F (2004) Regional climate modeling: progress, challenges, and prospects. J Meteorol Soc Jpn Ser II 82:1599-1628

Wells N, Goddard S, Hayes MJ (2004) A self-calibrating Palmer drought severity index. J Climate 17:2335-2351

Weng H, Ashok K, Behera SK, Rao SA, Yamagata T (2007) Impacts of recent El Niño Modoki on dry/wet conditions in the Pacific rim during boreal summer. Clim Dyn 29(2-3):113-129. doi:10.1007/s00382-007-0234-0

Wilby RL, Wigley TML (1997) Downscaling general circulation model output: a review of methods and limitations. Prog Phys Geogr 21:530-548

Wilby RL, Wigley TML (2000) Precipitation predictors for downscaling: Observed and general circulation model relationships. Int $\mathbf{J}$ Climatol 20:641-661

Wilby RL, Wigley TML, Conway D, Jones PD, Hewitson BC, Main J, Wilks DS (1998) Statistical downscaling of general circulation model output: a comparison of methods. Water Resour Res 34:2995-3008

Wilby RL, Hay LE, Gutowski WJ, Arritt RW, Takle ES, Pan Z, Leavesley GH, Clark MP (2000) sHydrological responses to dynamically and statistically downscaled climate model output. Geophys Res Lett 27(8):1199-1202. doi:10.1029/199 9GL006078

Wilby RL, Charles SP, Zorita E, Timbal B, Whetton P, Mearns LO (2004) Guidelines for use of climate scenarios developed from statistical downscaling methods, technical report, Intergovt. Panel on Climate Change, Geneva, Switzerland 